\title{
Acoustic, Electric and Virtual Noise: The Cultural Identity of the Guitar
}

\author{
Gavin Carfoot
}

$\mathrm{T}$ he guitar is a form of music technology through which dominant sociocultural and musical discourses are frequently enacted and challenged. In particular, the guitar has often played a part in challenging dominant discourses through its ability to highlight the cultural boundaries between noise and musical sound. This fact can be seen in each of the instrument's ever-changing technological forms-from acoustic to electric and virtual. This article begins by examining quite broadly how musical instruments help to define the concepts of "noise" and "musical sound." Next, I focus on some specific historical events that typify the move from acoustic to electric guitars. Finally, I discuss the recent technological shift toward virtual guitars: specifically, how virtual guitars have resulted in innovative possibilities, but also how common nostalgic views toward the guitar are reiterated in virtual technologies.

The impact of virtual guitar technology has not yet been studied to a great extent, no doubt because the technology has only recently become widespread in the mass market. Furthermore, until recently, much study of the guitar was narrowly focused on the origins of the modern classical guitar. However, there have been some recent studies of the guitar and the worldwide "guitar diaspora," including edited collections by Andy Bennett and Kevin Dawe, as well as Victor Anand Coelho [1]. Similarly, in influential studies by Robert Walser and Steve Waksman, the electric guitar has garnered some significant scholarly attention, most of which has interpreted the instrument as a means to better understand the sociocultural contexts of popular music [2].

\section{NOISE, SOUND AND MUSICAL INSTRUMENTS}

Within the contemporary environment, the role of sonic technologies is often organizational: From mall music to cell phones, sound is used to structure and direct our lives. However, this representational and ordering use of sound is neither new nor unique to new-media technologies. The ringing of a telephone bell and the whine of a siren both exemplify similar uses of sound. Whenever a sound wave changes from an indistinguishable noise into a meaningful sound, it can only do so in relation to the relevant sociocultural milieu. Just as noises and sounds in everyday life gain meaning through their social and cultural environment, so too are the terms "sound" and "noise" continually changing in relation to music. Jacques Attali famously noted that musical meaning is often created through the disruptive power of noise. The use of different

Gavin Carfoot (lecturer, musician), Queensland Conservatorium, Griffith University, PMB 50 Gold Coast Mail Centre, Bundall 9726, Queensland, Australia. E-mail: $<$ g.carfoot@griffith.edu.au> sounds in music relies upon an ever-changing standard definition of what actually distinguishes acceptable music-sound events from pure "noise" [3]. In an even broader sense, we can think of "noise" as any information that appears to exist outside of the representational systems that we are accustomed tothat which appears to be "chaotic" or "random," for example. Thus, in music, the injection of noise can take any number of forms, from the literal use of noise generators (white or pink noise, for example) right through to a particular type of compositional method that breaks with pre-existing musical forms, such that listeners might describe it as "not even music at all" or "just noise, not music."

For example, John Cage's redefinition of the musical soundscape emerged in part from his Zen-inspired questioning of the separation between everyday noises and musical sounds. Another, more contemporary example can be found in the "glitch" genre of electronic dance music, in which producers use noises such as pops and scratches - those "accidental" aspects of recorded sound that are usually ignored or considered extraneous to the musical work-and incorporate these noises into musical compositions using the sampler. However, just as the sampler has been used to introduce so-called noise into music, it is also often used for its original purpose: that is, to approximate "real" instruments, supposedly as "accurately" as possible. In both ways of using the sampler, it becomes clear that musical instruments can act as primary sites of contestation through which the definition of "noise" is actively enacted and challenged, but also that instruments may act as sites through which these definitions of noise are played out and reinforced. In a sense, all musical instruments (not just recent electronic instruments) may function in this way: that is, they have the potential to dramatically alter the ways of delineating noise and music, even though the ways that they use are not always so radical. New musical technologies may just as easily function to reinforce cultural notions of "musicality" and "properly ordered" sound as they may act as utopian harbingers of novelty.

\section{From Acoustic To Electric}

The history of the guitar is dotted with instances in which the distinction between noise and musical sound has been challenged or reinforced. However, the traditional historical canon 
of the guitar as an instrument does not necessarily incorporate these sites of "noisy" contestation. When narrated in a dryly analytical organology, the history of the guitar traces a route from 15th- and 16th-century Spanish, Italian and French instruments such as the chitarra to the Portuguese vihuela and their dispersion through colonization. Despite this clear ancestry, the history of the guitar is not just the story of a contained, linear development within a unified musical tradition. Rather, it is the story of crosscultural exchange and transformation, to the extent that it becomes difficult to establish orthodoxy in the instrument's history. Victor Anand Coelho describes the story of the guitar as one of "multiple and overlapping histories" [4]. Especially given the ubiquitous role of the guitar in the 20th century, the usefulness of studying the guitar lies not in accurately mapping a linear, historical and geographical distribution of the instrument. Rather, it is through tracing the complex, web-like interactions within and across cultures that we are able to learn more about contemporary musical cultures and practices [5]. Few musical technologies span the broad social, cultural and musical relationships that can be found through studying the guitar. Even the revered piano tends to be more confined to the Western art music tradition than does the guitar. Furthermore, while musicians and writers might be susceptible to the techno-utopianism that surrounds recent digital music-making technologies, the scope and influence of digital musicmaking is generally more limited to musicians from relatively affluent circumstances. Because the guitar has traversed so many 20th-century musical cultures, it offers a useful way to study the sociocultural ideologies that underpin the use of new technologies.

For an example of the above, Andrés Segovia's infamous "invention" of the modern classical guitar tradition was based upon, and actively produced, a series of culturally constructed ideologies around the instrument: Namely, that it was indeed a "great" instrument, undeservedly neglected in the concert tradition. His promotion of the guitar extended to his connection with contemporary luthiers who crafted guitars that were significantly louder and supposedly more "expressive." Initially, Segovia's promotion of the guitar injected a "noise" into the concert music tradition, in the sense that it introduced a new, disruptive type of sound into the rarefied world of concert music. However, follow- ing the gradual acceptance of the instrument in this setting, much writing about the guitar in the early and mid20th century aimed to reinforce the development of an orthodox concert tradition.

The development of the electric guitar in the 1940 s and 1950 s came as something of a threat to this ideology. For example, Frederic Grunfeld's The Art and Times of the Guitar did not even recognize the electric guitar as a guitar at all [6]. Harvey Turnbull's The Guitar: From the Renaissance to the Present Day typified this attitude. As Turnbull wrote in 1974: "A number of offshoot guitars have appeared, ranging from the flamenco guitar to the ubiquitous electric guitar, and these, too, ... have developed their own techniques. Some of these techniques involve the use of a plectrum to produce sounds, thus limiting the musical possibilities" [7]. That Turnbull's work masqueraded as an all-encompassing historical survey-and yet dismissed the creative and musical possibilities of the electric guitar, even in 1974-demonstrates how musical instruments can act as a locus for culturally inscribed musical values. In the case of Turnbull's dismissal of guitar music produced with a plectrum, the physical and technical demands of the guitar are used to justify a whole set of value judgments about musical style and taste-judgments that privilege the more "human," "natural" and musical acoustic guitar over and above the more "machine-like," "artificial" and noisy electric guitar.

Perhaps the most well-known incident demonstrating this inscription of cultural values within a musical instrument is Bob Dylan's infamous performance at the 1965 Newport Folk Festival, where he was purportedly booed off stage for appearing with an electric guitar and forced to return to the stage with an acoustic instrument [8]. A similar incident occurred at the 1968 Festival, when electric guitarist Buddy Guy performed with highvolume amplification and feedback. Waksman describes Guy's presence as representing "the status of noise, of an approach to sound that could not be readily assimilated into the presiding social and aesthetic assumptions of the festival" [9]. This clash between acoustic and electric sound has functioned as a key event in the history of musical instruments and it can be interpreted in a number of ways. It might be seen as a matter of "authentic," acoustic-based folk music performance set in opposition to inauthentic and commodified musical performance. Al- ternatively, it may be thought of as a battle of volume, wherein Guy's loud city blues had an "unfair advantage" and drowned out other performers at Newport [10]. Overall, the fact that such "anti-electric" sentiments were expressed so strongly is remarkable-especially given that electric guitars were a widely accepted part of the popular culture of the day. This would seem to demonstrate just how musical instruments are deeply inscribed with different social and musical values in different contexts. Yet another way to understand these events is by thinking about how the thresholds between musical sound and noise may have been crossed. In each case, we can see how sociocultural notions of "musical sound" were breached by the incursion of "chaotic noise." In each case, also, we can observe a re-configuration of these notions, along with an attendant "re-making" of the social discourses that inform the "legitimate" use of music technologies such as the guitar.

The move from acoustic to electrified instruments is only one aspect of the rich history of the guitar, and "the electric guitar has a much broader importance with regard to sound than the electric/ acoustic divide would suggest" [11]. The ideology surrounding the instrument is also intimately tied to discourses of gender, race, age and generation, nostalgia, and the powerful effect of sound itself [12]. Furthermore, despite the aforementioned clash between "folk ideology" and "rock revolution," the electric guitar has usually held the lauded mantle of authenticity in popular music. Indeed, the electric guitar holds a rarefied place in rock criticism as an icon of mass resistance and a symbol of authentic, artistic expression.

In this regard, few experiences in the popular music of the 1960s were as provocative as Pete Townshend's manic smashing of guitars and trashing of amplifiers, or Jimi Hendrix's guitar sacrifice through burning. As Tom and Mary Anne Evans write about Hendrix, through "the volume and aggression of his sound, [Hendrix] alienated many outside the rock circle and public. But the audio visual feast he provided, with smashed and burning guitars, fulfilled his audience's demand for a cathartic Experience" [13]. This catharsis can be likened to a "reconfiguration" of the representational systems used to order and regiment noise and sound in music. Thus, in the case of Townshend, we find that

Sound manipulation, distortion and physically violent performances pointed 
to a new concept of the electric guitar. From being a conventional musical instrument on the one hand or a stage prop on the other, the electric guitar became the heart of a sound system, in which artificially induced noise was as legitimate as a musical note [14].

In other words, these noises became a part of the representational systems that both musicians and audiences recognize as "belonging" to music. This resulted in not only an expanded dramatic and the atrical palette in performance but also a new palette of sounds that became intertwined with various popular music styles and genres. The same can be said of guitar-induced amplifier feedback: Jeff Beck saw it first as an annoying noise, a side effect of playing at high volume. However Beck subsequently learnt to use it as a highly expressive musical device (as have many guitarists since then). Similarly, Townshend is said to have first smashed his guitar by accident, although this ac cident was subsequently incorporated into the system of musical representation. In each case, the cultural and musica identity of the guitar has incorporated these originally chaotic, sometimes destructive events into established systems of musical signification.

Art that destroys its very means of creation has particularly strong links with the era of the 1960s, most especially in the avant-garde. When it came to guitarsmashing antics, Townshend himself referenced Gustav Metzger, a Fluxus artist and author of a manifesto on auto destructive art [15]. In the 20th-century avant-garde, artistic acts of destruction were commonly used as symbolic gestures in the creation of meaning, often specifically in the expression of politicized critique. As such, works such as Metzger's self-destructive painting in acid on nylon or Jean Tinguely's burning Homage to New York (1960) are usually interpreted as representing a very pointed critique of capital and the role that the contemporary arts play in capitalist society. Similarly, Townshend and Hendrix's acts can be interpreted as symbolic representations of some specific social and cultural critique. As an interpretive strategy, how ever, the understanding of destruction in art as a politics of critique is not exhaustive. The destruction of an instrument is provocative for a number of complex social, cultural, musical and technological reasons. It is not only a display of social resistance. It can also be seen as an extreme, athleticized form of expressive virtuosity, for example. Most interestingly, it can also be seen as a means of creating an infinite array of possible meanings through its own creative destruction, a fact that Metzger recognized. As Ross Birrell writes:

In a manner that echoes both Hindu creation myth and Bakunin's anarchism (from the beginning Metzger has aligned Auto-destructive Art with auto-creative art), Metzger views destructivity as integral to any act of creativity: "Art arises from the feeling and the knowledge that the line between a generative and a destructive reality is paper thin" [16].

As such, these gestures also enact a remaking of social, cultural, music and technological discourses. Part of this remaking relies upon a transgression between discrete elements: between musical sound and noise, between performer and instrument, between representational and non-representational gestures. Smashing and burning an electric guitar acts as a symbolic representation of new potentials in cultural production and often demonstrates the crossing of culturally constructed thresholds between musical sound and noise.

In a broad sense then, the noisemaking of Hendrix and Townshend holds much in common with the digital revolution of dance music (including the "glitch" genre mentioned above): Both sets of musicians inject noise in the musical strata as a means of resistance and a means of creating the new. In some ways echoing Attali, philosophers Gilles Deleuze and Félix Guattari would describe it as a process of "territorialization": It begins with the use of noise to destroy preexisting musical territories; noise is then able to de-territorialize the culturally constructed notion of musical sound, and this noise is in turn re-territorialized into a new definition of what constitutes musical sound [17]. In the case of Hendrix and Townshend, the de-territorialization of their noise-making acts is also intimately connected to their bodily and material transgressions: By destroying a material object that is invested with so much cultural significance, they were redefining the ways in which musical instruments could be used to organize musical sound, noise and the human body. To caress an instrument, to live with it, for it to become part of you: These are intimate and introspective acts. To smash and burn an instrument is an aggressive and transgressive act: It introduces a chaotic "sonic noise," in addition to a "sociocultural noise," into the aural-cultural landscape. It reminds us that the thresholds between "musical sound" and "noise" are socially created and culturally situated and these thresholds are often manifested within-and challenged bythe ways that musical instruments are used and abused.

\section{FROM ELECTRIC TO VIRTUAL}

It is not yet entirely clear how disruptive noise-such as that of Hendrix and Townshend's electric guitars-might be realized within the new breed of consumer digital guitar technologies. Until recently, digital guitars have been relatively uncommon, although some industry standards have arisen [18]. Experimental instruments have been available, but the influence of these instruments in the broader world of guitar players has been quite minimal. There are a number of reasons for this, including the inability of small-scale inventors to mass-produce and effectively market niche technological products to the industry. Overall, however, the ingrained culture and ideology of guitarists and guitar makers has been the primary reason why digital technologies have only just started to have an impact upon the mass market.

To better understand this situation, we only need to examine the types of digital guitar technology that are now popular [19]. In most new digital guitar technologies, the aim is usually to re-create existing orthodoxies in instrument design: that is, to digitally model the electric guitar and guitar technologies in software as transparently as possible. In this practice we can observe how the process of creating a "virtual" guitar is usually played out. While the term "digital guitar" can be used quite accurately to describe some of these technological hybrids, in a more descriptive sense they are virtual guitars, because the explicit aim is to "virtualize" some material reality into a "non-physical" form. Related to this process is the concept of a "virtual reality" in which a facsimile of a supposedly "real" reality is created, or in which a totally new "digital reality" is fabricated. As a concept popular in postmodern and poststructuralist theory, this idea of the virtual is often used to illustrate how the era of late capitalism has introduced some major shifts in our relationship to "reality." The process of virtualization has occurred in so many aspects of everyday life in the first world, and as such it is predictable that musical instruments would be incorporated into this process.

Since the adoption of MIDI technology and the use of digital audio, virtualization (in one form or another) has 
been synonymous with the "cutting edge" of music technology. In the wake of electronic dance music, the sampler became the symbol of musical resistance par excellence. It also came to be a symbol of subversion and a non-representational way of co-opting noise into music making. Often the ideology behind electronic dance music has been targeted at a prevailing rock ideology, with rock's reliance on supposedly "material" and "human" guitar technology-as opposed to the newer "virtual" and "machinic" possibilities of the turntable and sampler. Because the ideology of machine-produced music became so intertwined with the notion of cultural resistance, it has been difficult to escape the elements of techno-utopianism that have accompanied it. In a broader sense, however, the use of musical machines holds much in common with the use of the guitar in rock. That is, both samplers and guitars are types of technology and machines, and they can both activate a movement from noise to musical sound, in the way that Attali sees as central to music [20].

Many recent developments in virtual guitar technologies demonstrate a desire to replicate specific, highly desirable guitar technologies (usually in the form of vintage guitars and amplifiers). Other aspects of virtual luthierie represent a desire to re-technologize the guitar by creating new and distinctively virtual possibilities. The luthier who works with virtual guitar technology usually attempts to tread the fine line between these two possibilities: creating something novel while at the same time acknowledging that musicians often identify very personally with the existing cultural identities of their instruments. However, due to the strength of these cultural identities, virtual guitars are often positioned as more evolutionary than revolutionary in relation to the contemporary musical and technological milieu.

Sometimes the novelty of a virtual guitar is simply the virtuality of the medium itself. In the case of modeling technology, the main difference between a virtual guitar and an electric guitar lies in the former's ability to sound like any number of guitars-a Les Paul, a Stratocaster or even a sitar-all with the flick of a knob. In this case, virtualization provides a kind of "utility." It radically alters the degree of speed with which one can access different sounds (in much the same way as a keyboard instrument or sampler) although it injects very little "noise" into the musical milieu because it draws so strongly upon pre-existing forms.
Other options, such as the ability to assign different sounds to different strings, and different triggering options for different notes in a MIDI guitar setup, offer greater possibilities for disruptive virtual guitars. The ability to instantly reconfigure guitars into alternate and microtonal tunings offers similar opportunities. The material aggression of smashing and burning an electric guitar is not something that has been modeled, although in any case, the creative destruction of the guitar in the virtual realm has the potential to take a very different form. In a sense, the very virtualization of the guitar is an introduction of noise through a metaphorical destruction of the guitar in its material form. That this virtualization is often followed by a duplication of preexisting musical and sonic values is not reason to believe that virtual guitars will forever be "re-creative" of ideal, physical forms. The virtual guitar's uniqueness may prove to be its ability to maintain just enough of the instrument's form so that it remains "a guitar," but to continually push at the boundaries of this form. Rather than the maintenance of a respect for idealized types of vintage guitar, the future of the virtual guitar might lie in the same sense of creative destruction and "play" that Townshend brought to his electric guitar. As he said, "I don't have a love affair with a guitar, I don't polish it after every performance; I play the fucking thing" [21].

\section{CONCLUSION}

The move from acoustic to electric guitars is one of the most interesting aspects of the history of musical instruments. This is not only because of the technological shift that it represented, but also because it highlighted some major changes in the social and musical discourses of the times. Similarly, new developments in guitar technology may introduce shifts in the ideology surrounding this instrument-although in light of recent developments, the move from electric to virtual guitar has not resulted in radical cultural re-definitions of what actually constitutes "a guitar." This is because the sociocultural ideologies that are inscribed in musical instruments cannot be divorced from those instruments. It may be that virtual guitars continue to push at the boundaries of their own form. At present, however, the broad base of musical consumers of virtual guitar technology is defined as much by a nostalgia in the virtualization of guitar technologies as by a desire to explore the possibilities of the new.

\section{References and Notes}

1. Andy Bennett and Kevin Dawe, eds., Guitar Cultures (Oxford and New York: Berg, 2001); Victor Anand Coelho, ed., The Cambridge Companion to the Guitar (Cambridge, U.K.: Cambridge Univ. Press, 2002).

2. Steve Waksman, Instruments of Desire: The Electric Guitar and the Shaping of Musical Experience (Cambridge, MA: Harvard Univ. Press, 1999); Robert Wridge, Running with the Devil: Power, Gender and Madness in Heavy Metal Music (Hanover, NH: Wesleyan Univ. Press, 1993).

3. Jacques Attali, Noise: The Political Economy of Music, Brian Massumi, trans. (Minneapolis, MN: Univ. of Minnesota Press, 1985)

4. Victor Anand Coelho, "Picking through Cultures: A Guitarist's Music History," in Coelho [1] p. 3.

5. Deleuze and Guattari refer to this kind of web as a "rhizome," whereby arborescent (hierarchical, treelike) structures are contrasted with rhizomatic structures (those that operate through a proliferation of multiple connections, like a strawberry plant that throws out runners). See Gilles Deleuze and Félix : Copitasm and Schizophrenia (Minneapolis, MN: Univ. of Minnesota Press, 1987).

6. Frederic Grunfeld, The Art and Times of the Guitar (London, 1969).

7. Harvey Turnbull, The Guitar: From the Renaissance to the Present Day (New York: Scribner's, 1974) p. 126.

8. Since the media reports of the time, there have been re-tellings of this incident that have variously stressed the fervor of the crowd and the reaction from other musicians.

9. Waksman [2] p. 7 (emphasis added).

10. In fact, the desire for greater amplitude has also been shared by acoustic musicians and instrument makers, in the development of luthierie techniques in the construction of concert classical and Spanish guitars, as well as the louder and larger-body Dreadnought steel string acoustic, or the American archtop ("f-hole") guitar, originally designed to better "cut through" the loud horn sections of swing-era big bands.

11. Waksman [2] p. 7.

12. John Ryan and Richard A. Peterson, "The Guitar as Artifact and Icon: Identity Formation in the Babyboom Generation," in Bennett and Dawe [1] p. 111. Despite acknowledging the broad array of interpretative strategies that Steve Waksman uses for understanding the electric guitar, Ryan and Peterson tend to reduce their reading of the vintage guitar market to the ascription of a generational nostalgia.

13. Tom Evans and Mary Anne Evans, Guitars: $M u$ sic, History, Construction and Players from the Renaissance to Rock (New York and London: Paddington sance to Rock (New
Press, 1977) p. 409

14. Evans and Evans [13] p. 409 (emphasis added).

15. This is complicated somewhat by the originally "accidental" event that triggered Townshend's initial fetish for destroying musical equipment. Metzger is also known to have lectured at the same art school that Townshend attended. See his first manifesto on auto-destructive art in Gustav Metzger, Damaged

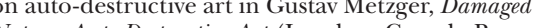
Nature, Auto-Destructive Art (London: Coracle Press, 1996).

16. Ross Birrell, Introduction to Gustav Metzger (1996) Available at $<$ www.autogena.org/Breathing/Gustav/ birrell.html>, accessed 30 November 2005 .

17. Deleuze and Guattari [5]. Deleuze and Guattari often relate this process to Messiaen and Boulez.

18. For example, see Roland's VG guitar systems, which incorporate MIDI technology into a traditional guitar through the use of a specialized pickup. 
19. In the first instance, there are guitars, the mate rial form of which is almost identical to a standard electric guitar, but with the addition of digital I/O capabilities. Brian Moore's iGuitar is probably the most widely dispersed example, and it has used a range of I/O options, including MIDI and USB. Gibson's Digital Guitar, which uses Ethernet I/O, has been much publicized, but its date of release to the consumer market has been frequently postponed. A variation on these instruments is the employment of onboard digital modeling, which effectively provides a string-based control surface for the performance of a modeling synthesizer. In the case of Line 6' Variax, the guitar's sounds can be altered with a software editor running on PC. Other manufacturers uti- lize purely software-based augmentations to the tradition electric guitar, sometimes including dedicated audio interfaces for guitar and software modeling of famous amplifiers and electronic effects (for example, see plug-ins such as Line 6's Amp Farm and standalone applications such as Native Instrument Guitar Rig). In the purely vitual ream, software incrume tars, synthesized approximations or combinations of both types of sounds are also common.

20. Attali [3].

21. Pete Townshend quoted in Evans [13] p. 411 (emphasis in original)
Manuscript received 1 June 2006.

Gavin Carfoot is a lecturer in popular music at the Oueensland Conservatorium, where he teaches music technology, music theory and popular music studies. His research is largely inter-disciplinary, including broad-based work in cultural studies and critical theory. He is also active as a producer, composer and performer in various styles of popular music.

\section{Leonardo Celebrates Leonardo da Vinci Special Section of Leonardo, 2007-2008}

In celebration of Leonardo journal's 40th anniversary, we are calling for essays related to Leonardo da Vinci and his concerns regarding the relationship between art and science. We are interested in submissions in which Leonardo's own concerns serve as a springboard for looking toward the present. What, building upon Leonardo's ways of thinking, can artists and scientists tell each other today? We also seek original accounts of his visual art, of his achievements as a proto-scientist and of the relation between his concerns with science and with visual art.

Recommended length: 2,500-3,500 words.

Illustrations per essay: 5-8 black-and-white images; possibly one color image.

Prospective authors are encouraged to review the Leonardo Author Guidelines on the Web: www.leonardo.info. (Follow the links: Publications, Information for Authors, Leonardo Print Journals, Editorial and Illustration Guidelines.)

All papers will be peer-reviewed prior to acceptance for publication.

Submissions deadline: 15 January 2007.

Please send inquiries and submissions to Guest Editor David Carrier: <david.carrier@cwru.edu>. 